\title{
KARAKTERISTIK LAJU RESAPAN LUBANG BIOPORI PADA BEBERAPA JENIS SAMPAH ORGANIK
}

\section{DEWA GEDE JAYA NEGARA ${ }^{1)}$, AGUSTONO SETIAWAN ${ }^{2)}$, HUMAIRO SAIDA ${ }^{3)}$, ADRI GUNAWAN ${ }^{4)}$}

\section{Jurusan Teknik Sipil Fakultas Teknik Universitas Mataram}

e-mail: ${ }^{1)}$ jayanegara@unram.ac.id, ${ }^{2)}$ agustonos@unram.ac.id, ${ }^{3)}$ h.saidah@unram.ac.id,

\begin{abstract}
ABSTRAK
Banyak upaya yang telah dilakukan berbagai pihak dalam mengatasi masalah sampah dan banjir,di daerah permukiman yang mulai berkembang, salah satunya adalah dengan memanfaatkan sampah organik sebagai pengisi biopori untuk perbaikan resapan pada lapisan tanah dan memproduksi kompos. Teknologi lubang resapan biopori dapat memanfaatkan sampah organik untuk pengisi media biopori, yang dimanfaatkan sebagai sumber makanan oleh biota di dalam lapisan tanah. Penelitian ini bertujuan untuk mengetahui laju resapan biopori pada pemanfaatan beberapa jenis sampah organik seperti (1)jerami,(2)dedauan dan (3) sampah rumah tangga. Biopori dibuat dari pipapvc 4" dan panjangnya $1 \mathrm{~m}$ dengan pemasangan ke dalam tanah $80 \mathrm{~cm}$ dan sisanya di atas permukaan tanah $20 \mathrm{~cm}$ untuk keperluan pengujian dengan jumlah 12 titik uji dan diuji dilakuka setelah 7 hari hinggi 21 hari. Untuk lubang biopori tanpa bahan pengisi diperoleh nilai laju resapan tertinggi sebesar $85 \mathrm{~cm} / \mathrm{jam}$ dan terendah sebesar 42.167 $\mathrm{cm} / \mathrm{jam}$. Jenis sampah jerami diperoleh nilai laju resapan (infiltrasi) sebesar $179.34 \mathrm{~cm} / \mathrm{jam}$ dan nilai laju resapan terendah $86.770 \mathrm{~cm} / \mathrm{jam}$., dengan rata-rata $113.56 \mathrm{~cm} / \mathrm{jam}$. Pada pengisi dengan sampah dedaunan diperoleh laju resapan (infiltrasi) tertinggi sebesar $100.111 \mathrm{~cm} / \mathrm{jam}$ dan terendah $59.743 \mathrm{~cm} / \mathrm{jam}$, nilai ratarata sebesar $84.69 \mathrm{~cm} / \mathrm{jam}$. Sedangkan pada jenis sampah rumah tangga diperoleh nilai laju resapan terendah sebesar $38 \mathrm{~cm} / \mathrm{jam}$ dan tertinggi sebesar $100.111 \mathrm{~cm} / \mathrm{jam}$, dan rata-rata $52.979 \mathrm{~cm} / \mathrm{jam}$. Pada umur sampah 7 hari terjadi laju resapan tertinggi dan setelah sampah berumur 21 hari sudah seharusnya diganti dengan yang baru.
\end{abstract}

Kata Kunci : lubang biopori, bahan pengisi, laju resapan

\begin{abstract}
Many efforts have been made by various parties in overcoming the problem of waste and flooding, in residential areas that are starting to develop, one of which is by utilizing organic waste as a biopore filler to improve soil absorption and produce compost. The biopore infiltration hole technology can utilize organic waste to fill biopore media, which is used as a food source by biota in the soil layer. This study aims to determine the rate of biopore infiltration in the use of several types of organic waste such as (1) straw, (2) leaves and (3) household waste. Biopori is made from pipapvc 4 " and $1 \mathrm{~m}$ in length with installation into the ground $80 \mathrm{~cm}$ and the rest above the soil surface $20 \mathrm{~cm}$ for testing purposes with a total of 12 test points and tested after 7 days to 21 days. For biopore holes without filler, the highest absorption rate was $85 \mathrm{~cm} /$ hour and the lowest was $42,167 \mathrm{~cm} /$ hour. The type of straw waste obtained infiltration rate of $179.34 \mathrm{~cm} / \mathrm{hour}$ and the lowest infiltration rate of $86,770 \mathrm{~cm} /$ hour, with an average of $113.56 \mathrm{~cm} /$ hour. In the filler with leaf litter, the highest infiltration rate was 100,111 cm / hour and the lowest was $59,743 \mathrm{~cm} / \mathrm{hour}$, with an average value of $84.69 \mathrm{~cm} /$ hour. Whereas for household waste, the lowest absorption rate was $38 \mathrm{~cm} /$ hour and the highest was 100,111 cm / hour, and the average was $52,979 \mathrm{~cm} /$ hour. At the age of 7 days the waste has the highest absorption rate and after the waste is 21 days old it should be replaced with a new one.
\end{abstract}

Keywords: biopore holes, filler waste, infiltration rate 


\section{PENDAHULUAN}

Pemanfaatan sampah organik untuk pembuatan kompus sudah banyak dilakukan, tetapi sampah organic untuk memicu peresapan air merupakan hal yang menarik dan perlu dipelajari lebih lanjut manfaatnya.Dengan banyaknya kawasan resapan air yang diperkeras seperti dengan paving block, maka resapan air ke dalam air tanah akan berkurang dan oleh sebab itu perlu diatasi karena akan berpotensi menimbulkan genangan dan menurunkan ketersediaan air tanah. Salah satu usaha yang dapat meningkatkan resapan air hujan ke dalam tanah adalah dengan teknologi lubang resapan biopori. Lubang resapan biopori adalah lubang silindris yang dibuat secara vertikal ke dalam tanah dengan diameter $10 \mathrm{~cm}$ dan kedalaman $100 \mathrm{~cm}$ atau kurang jika air tanah dangkal. Ukuran diameter $10 \mathrm{~cm}$ merupakan ukuran yang sudah dipikirkan secara cermat oleh Kamir R. Brata. Jika kurang dari $10 \mathrm{~cm}$ maka akan sulit untuk memasukkan sampah ke dalam lubang tersebut. Kedalaman $100 \mathrm{~cm}$ juga diperhitungkan agar tersedia cukup oksigen agar sampah yang dimasukkan segera diolah oleh organisme tanah sebelum mengalami pembusukan yang menghasilkan gas metan. Kedalaman yang kurang dari kedalaman air muka tanah tersebut juga dimaksudkan agar air yang masuk mengalami proses bioremediasi sebelum masuk ke dalam air tanah. (Brata, 2008).

Menurut Brata (2008) dalam BR.Ginting (2010) biopori merupakan ruang atau pori dalam tanah yang dibentuk oleh makhluk hidup, seperti mikroorganisme tanah dan akar tanaman. Bentuk biopori menyerupai liang (terowongan kecil) di dalam tanah dan bercabang-cabang dan sangat efektif untuk menyalurkan air dan udara ke dalam tanah. Dengan adanya berbagai jenis sampah di lapangan, perlu juga diketahui pengaruh dari penggunaan bahan pengisi lubang biopori terhadap kemampuan resapannya jika jenis sampahnya yang berbeda. Hal ini diperlukan agar diperoleh potensi resapan yang yang lebih besar dari jenis sampah yang tersedia. Dengan banyaknya sampah dedauan, sampah jerami dan sampah rumah tangga di wilayah sekitar kampus dan permukiman, maka perlu kiranya diketahui apa pengaruhnya penggunaan bahan pengisi biopori tersebut terhadap kemampuan laju resapan biopori. Mana yang paling baik diantara jenis sampah organik tersebut dalam melakukan peresapan air pada lahan agar diketahui. Dengan diperolehnya hasil uji ini maka akan didapat beberapa alternatif yang potensial untuk pengisian biopori disekitar wilayah ini dimasa mendatang.

\section{Rumusan Masalah}

Adapun rumusan masalah dalam penelitian ini yaitu:

1. Bagaimana laju infiltrasi lubang resapan biopori maksimum pada jenis bahan sampah daun-daunan, sampah rumah tangga, sampah jerami dan tanpa bahan pengisi ?,

2. Bagaimana jenis sampah potensi digunakan sebagai bahan pengisi LRB ?

3. Bagaimana waktu penggantian sampah.

\section{Tujuan dan Manfaat}

Tujuan penelitian ini adalah untuk dapat mengetahui besar laju infiltrasi lubang resapan biopori maksimum pada jenis bahan sampah daun-daunan, sampah rumah tangga, sampah jerami dan tanpa bahan pengisi. Mengetahui jenis sampah potensi digunakan sebagai bahan pengisi LRB dan mengetahui waktu penggantian sampah.

Manfaat yang diharapkan hasil penelitian ini adalah dapat memberi masukan dan informasi dalam pemilihan sampah yang potensial dari yang diujikan untuk digunakan dalam meningkatkan resapan air pada pipa biopori pada pihak yang terkait.

\section{METODE PENELITIAN}

\section{Lokasi Penelitian}

Uji LRB dilakukan dikawasan areal Fakultas Teknik Universitas Mataram sebagai uji coba, sebagai upaya untuk meningkatkan resapan limpasan hujan ke dalam tanah karena areal halaman yang ada lambat laun akan terpasangi paving blok sehingga perlu ada inisiasi pengembalian resapan dengan biopori.

\section{Bahan dan pembuatan biopori}

Bahan yang digunakan adalah pipa diameter 4 inch sebanyak 12 buah dan sampah organik jerami, daun-daunan dan sampah rumah tangga. Pipa pvc dipotong dengan gergaji dengan ukuran $1 \mathrm{~m}$ sebanyak 12 buah potongan. Pipa yang telah dipotong kemudian dilubungi dengan bor tangan untuk pembuatan pori-pori pada sisi pipa secara teratur. Sampah organi jerami, dedauan dan sampah rumah tangga disiapkan sebagai bahan pengisi pada masing-masing 3 lubang pipa uji, dan 3 pipa yang lainnya tanpa bahan pengisi sampah sebagai kontrol. 


\section{Pemasangan biopori}

Pemasangan biopori dilakukan mengikuti skema rancangan pemasangan pipa biopori pada lahan uji seperti pada Gambar 1.

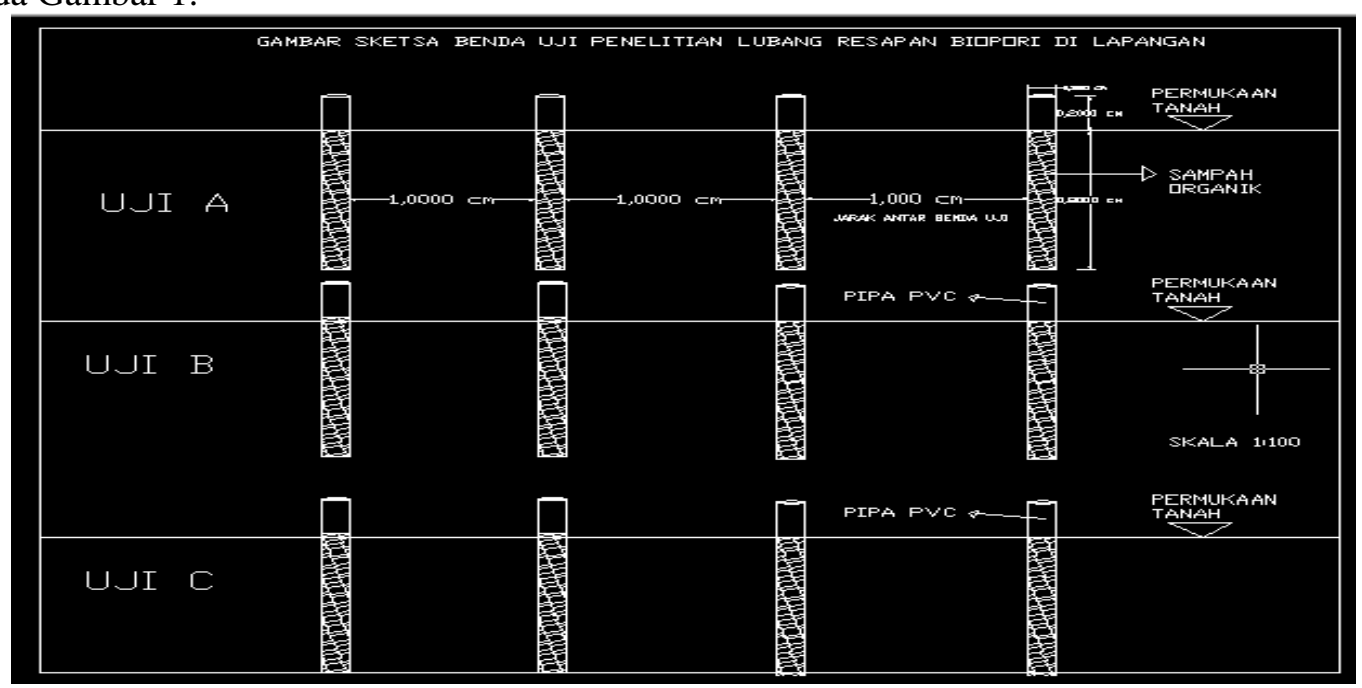

Gambar 1. Sketsa pemasangan pipa lubang resapan biopori

Setelah pipa pipa pori disiapkan maka dari 12 pipa yang disiapkan 9 buah pipa digunakan untuk uji sampah dan 3 buah pipa dipasang sebagai control tanpa diisi sampah. Pipa biopori dipasang $80 \mathrm{~cm}$ masuk ke dalam tanah dan $20 \mathrm{~cm}$ tersisa dipermukaan tanah pada semua pipa yang dipasang dan jarak antara pipa $1 \mathrm{~m}$.

Tahapan pengukuran laju resapan pada lubang biopori dilakukan sebagai berikut:

1. Memasukkan pipa pvc kedalam tanah, diatas lubang diletakkan pipa pvc tambahan dengan ukuran $20 \mathrm{~cm}$.

2. Bibir lubang diperkuat dengan tanah agar semakin padat.

3. Mengisi pengisi sampah organik pada pipa biopori yaitu sampah daun (A), sampah rumah tangga (B) dan jerami (C), masing-masig 3 variasi.

4. Setelah hari ke-7 sampai dengan hari ke-21, dilakukan diuji laju resapannya dengan cara memasukkan air ke dalam lubang pipa biopori sampai penuh \pm 191 .

5. Mengukur waktu resapan dengan stopwatch dengan interval setiap 5 menit

6. Mematikan stopwatch pada saat mendapatkan 3 nilai penurunan berturut-turut konstan.

\section{Penentuan Kebutuhan Lubang Resapan Biopori}

Jumlah lubang resapan biopori yang akan dibuat sebaiknya disesuaikan dengan luasan tanah yang ada. Menentukan jumlah lubang resapan biopori yang ideal adalah dengan menghitung menggunakan rumus berikut ini (Brata, 2008):

$$
\text { Jumlah LRB }=\frac{\text { Intensitas hujan }(\mathrm{mm} / \mathrm{jam}) \times \text { luas bidang kedap }\left(\mathrm{m}^{2}\right)}{\text { laju peresapan air per lubang (liter/jam) }}
$$

Suatu keadaan dengan hujan yang lebat memiliki laju resapan air 3 liter/menit atau 180 liter/jam pada tiap lubang. Apabila lubang dibuat memiliki diameter $10 \mathrm{~cm}$ dengan kedalaman $100 \mathrm{~cm}$ setiap lubang dapat menampung 7,8 liter sampah organik yang dapat diisi sampah organik pada $2-3$ hari. Jumlah LRB maksimum dapat dihitung menggunakan rumus (Meliala, 2015) dalam (Martha, 2018).

$$
\text { LRB Maksimum }=\frac{\text { luas Ruang Terbuka Hijau }}{\text { Luas Lahan Ideal } \mathrm{m}^{2}} \times \text { Jumlah Lubang Ideal }
$$

dengan;Q serap LR = Debit yang dapat diserap oleh LR $\left(\mathrm{m}^{3} /\right.$ detik), $\mathrm{Q}$ wilayah = Debit hujan yang jatuh di seluruh wilayah penelitian $\left(\mathrm{m}^{3} /\right.$ detik).

\section{Pembuat Lubang Resapan Biopori}

Pembuat lubang resapan biopori berdasarkan peraturan (Menteri Negara Lingkungan Hidup No.12, 2009) dapat diuraikan sebagai berikut:

Lokasi yang dapat dibuat lubang resapan biopori adalah daerah sekitar pemukiman, taman, halaman parkir dan sekitar pohon, serta pada daerah yang dilewati aliran air hujan.

Membuat lubang silindris ke dalam tanah dengan diameter $10 \mathrm{~cm}$, kedalaman $100 \mathrm{~cm}$ atau tidak melampaui kedalaman air tanah. Jarak pembuatan lubang resapan biopori antara $50-100 \mathrm{~cm}$;

Memperkuat mulut atau pangkal lubang dengan menggunakan: paralon dengan diameter $10 \mathrm{~cm}$, panjang minimal $10 \mathrm{~cm}$; atau adukan semen selebar $2-3 \mathrm{~cm}$, setebal $2 \mathrm{~cm}$ di sekeliling mulut lubang.

Mengisi lubang resapan biopori dengan sampah organik yang berasa dari dedaunan, pangkasan rumput dari halaman atau sampah dapur; dan

Menutup lubang resapan biopori dengan kawat saringan atau dob penutup pipa. 


\section{Laju Infiltrasi}

Laju infiltrasi diklasifikasikan menjadi tujuh kelas oleh Kohnke (1968) berdasarkan nilai laju infiltrasi konstan dan kategori laju reapan yang diperoleh mengacu pada sumber ini

\section{Permeabilitas (k)}

Permeabilitas adalah tanah yang dapat menunjukkan kemampuan tanah meloloskan air. Tanah dengan permeabilitas tinggi dapat menaikkan laju infiltrasi sehingga menurunkan laju air larian. Pada ilmu tanah, permeabilitas didefenisikan secara kualitatif sebagai pengurangan gas-gas, cairan-cairan atau penetrasi akar tanaman atau lewat. Sehingga gerakan air dalam tabung tersebut di anggap mempunyai kecepatan yang sama (Sutanto, 2005).

\section{Analisis Resapan Biopori}

Model persamaan kurva kapasitas infiltrasi yang dikemukakan oleh Horton adalah salah satu model infiltrasi yang terkenal dalam hidrologi. Horton mengakui bahwa kapasitas infiltrasi berkurang seiring dengan bertambahnya waktu hingga mendekati nilai yang konstant.

\section{HASIL DAN PEMBAHASAN}

\section{Analisis Jenis Tanah}

Pengujian tanah dilakukan pada laboratorium Geoteknik dan mekanika tanah Fakultas Teknik Universitas Mataram diperoleh hasil kadar air tanah uji 50.732\% dengan kandungan kerikil $21.98 \%$, pasir $54.13 \%$ dan butiran halus (lempung+lanau) $23.89 \%$. Berdasarkan hasil ploting tersebut pada grafik klasifikasi tanah diperoleh hasil termasuk pada jenis tanah pasir berlanau dengan hasil uji permeabilitas dan diperoleh nilai koefisien permeabilitas tanah $(\mathrm{k})$ sebesar $3.609 \times 10^{-3}$

\section{Laju Resapan Biopori Kontrol (LRBk) (tanpa pengisi sampah)}

Menurut Brata (2008) dalam waktu 14 hari setelah pemberian bahan organik, secara alami akan terbentuk biopori/liang-liang memanjang dan bercabang-cabang di dalam tanah akibat aktivitas cacing dan mikroorganisme lainnya. Dengan bertambahnya liang-liang di dalam tanah maka luas penampang permukaan tanah yang dapat menyerap air akan bertambah. Untuk menganalisis laju resapan biopori dalam studi ini digunakan rumusan uji infiltrasi. Pada lubang resapan biopori kontrol pada 3 lubang resapan biopori (LRBk) yaitu pada LRBk 1A,1B dan 1C hasil ujinya ditunjukkan pada Tabel1 sampai dengan Tabel 3 sebagai berikut.

\section{Lubang Resapan Biopori LRBk pada hari ke-7}

Menurut Murbandono (1999), bahwa pada lingkungan alam terbuka kompos bisa terbentuk dengan sendirinya. Melalui proses yang alami, rumput, daun-daunan, dan kotoran hewan lama-kelamaan membusuk karena kerja sama antara mikroorganisme dengan cuaca. Pengomposan dalam LRB menciptakan kondisi alami seperti disebutkan diatas, akan tetapi proses pengomposan dalam LRB bisa berlangsung lebih cepat dari kondisi biasa. Oleh karena itu pada pengujian ini dilakukan pengamatan ketika telah berumur 7 hari dan pada LRBk 1A dengan pemasangan pipa sampai 21 hari. Dalam satu hari, pengamatan dilakukan setiap interval 5 menit dan setelah terjadi 3 kali penurunan konstan dan data hasil uji dapat dilihat pada Tabel 1.

Tabel 1 Nilai penurunan laju infiltrasi sampai dengan nilai $\log$ (f0-fc)

\begin{tabular}{|c|c|c|c|c|c|c|}
\hline $\mathbf{t}$ (menit) & $\begin{array}{c}\mathbf{t} \\
(\mathbf{j a m})\end{array}$ & $\begin{array}{c}\Delta H \\
(\mathbf{c m})\end{array}$ & $\begin{array}{c}\text { f0 } \\
\text { (cm/jam) }\end{array}$ & $\begin{array}{c}\mathbf{f c} \\
(\mathbf{c m} / \mathbf{j a m})\end{array}$ & $\begin{array}{c}\text { f0-fc } \\
\text { (cm/jam) }\end{array}$ & $\begin{array}{c}\begin{array}{c}\log \\
(\mathbf{f 0}-\mathrm{Fc})\end{array} \\
\end{array}$ \\
\hline 5 & 0.083 & 28 & 336 & 75 & 261 & 2.417 \\
\hline 10 & 0.167 & 36 & 216 & 75 & 141 & 2.149 \\
\hline 15 & 0.250 & 41 & 164 & 75 & 89 & 1.949 \\
\hline 20 & 0.333 & 45 & 135 & 75 & 60 & 1.778 \\
\hline 25 & 0.417 & 48 & 115.2 & 75 & 40.2 & 1.604 \\
\hline 30 & 0.500 & 49 & 98 & 75 & 23 & 1.362 \\
\hline 35 & 0.583 & 49 & 84 & 75 & 9 & 0.954 \\
\hline 40 & 0.667 & 50 & 75 & 75 & 0 & 0.000 \\
\hline 45 & 0.750 & 50 & 75 & 75 & 0 & 0.000 \\
\hline 50 & 0.833 & 50 & 75 & 75 & 0 & 0.000 \\
\hline
\end{tabular}

Sumber : hasil analisis 
Dalam memperoleh besarnya k digunakan regresi hubungan linier antara waktu (jam) dan Log (f0-fc), selanjutnya nilai yang didapatkan dari hubungan linier tersebut di masukkan ke rumus Horton dan besar $\mathrm{k}$ yang diperoleh sebesar $8.824 \mathrm{~cm} / \mathrm{jam}$ kemudian digunakan dalam perhitungan pada Tabel 2.

Tabel 2 Nilai perhitungan laju infiltrasi

\begin{tabular}{|c|l|l|l|l|l|}
\hline \multirow{2}{*}{$\mathbf{k}$} & \multirow{2}{*}{$\mathbf{t}$ jam } & $\mathbf{f 0}$ & $\mathbf{f}$ & \multirow{2}{*}{$\mathbf{e}$} & $\mathbf{f}(\mathbf{t})$ \\
\cline { 3 - 4 } & & $(\mathbf{c m} / \mathbf{j a m})$ & $(\mathbf{c m} / \mathbf{j a m})$ & & $(\mathbf{c m} / \mathbf{j a m})$ \\
\hline 8.824 & 0.083 & 336 & 75 & 2.718 & 200.118 \\
\hline 8.824 & 0.167 & 216 & 75 & 2.718 & 107.402 \\
\hline 8.824 & 0.250 & 164 & 75 & 2.718 & 84.804 \\
\hline 8.824 & 0.333 & 135 & 75 & 2.718 & 78.168 \\
\hline 8.824 & 0.417 & 115.2 & 75 & 2.718 & 76.017 \\
\hline 8.824 & 0.500 & 98 & 75 & 2.718 & 75.279 \\
\hline 8.824 & 0.583 & 84 & 75 & 2.718 & 75.052 \\
\hline 8.824 & 0.667 & 75 & 75 & 2.718 & 75 \\
\hline 8.824 & 0.750 & 75 & 75 & 2.718 & 75 \\
\hline 8.824 & 0.833 & 75 & 75 & 2.718 & 75 \\
\hline
\end{tabular}

Berdasarkan Tabel 2 di atas, diketahui bahwa laju (resapan) infiltrasi yang diperoleh pada LRBk 1A terbesar pada menit ke-5 (0.083 jam) sebesar $200.118 \mathrm{~cm} / \mathrm{jam}$ dan laju infiltrasi konstan terjadi di menit ke 40-50 (0.667-0.833) sebesar $75 \mathrm{~cm} / \mathrm{jam}$, dan berdasarkan (Sukaresmi,2011) laju infiltrasi yang diperoleh termasuk sedang sampai cepat.

\section{Laju Resapan Lubang Biopori Pada pipa Kontrol}

Berdasarkan ke tiga data hasil pengujian nilai laju (resapan) infiltrasi pada uji lubang resapan biopori kontrol sebagai nilai rata-rata, maka hasil analisisnya ditunjukkan pada Tabel 3

Tabel 3 Nilai laju infiltrasi lubang resapan biopori kontrol

\begin{tabular}{|l|l|l|l|l|}
\hline \multirow{3}{*}{ Umur hari ke } & \multicolumn{2}{|c|}{$\begin{array}{c}\text { Nilai Laju Resapan (Infiltrasi) } \\
\text { (cm/Jam) }\end{array}$} & \multirow{2}{*}{$\begin{array}{c}\text { LR) } \text { rata-rata } \\
\text { (cm/jam) }\end{array}$} \\
\cline { 2 - 4 } & LRB 1A & LRB 1B & \\
\hline 7 & 75 & 80 & 100 & 85 \\
\hline 8 & 66.667 & 68.571 & 84 & 73.079 \\
\hline 9 & 73.5 & 78 & 81 & 77.5 \\
\hline 10 & 62.667 & 78 & 67.5 & 69.389 \\
\hline 11 & 60 & 74 & 63 & 65.667 \\
\hline 12 & 57.33 & 70 & 60 & 62.443 \\
\hline 13 & 57.333 & 68 & 58.5 & 61.278 \\
\hline 14 & 53.333 & 64 & 55.5 & 57.611 \\
\hline 15 & 52 & 60 & 52.5 & 54.833 \\
\hline 16 & 49.33 & 60 & 49.5 & 52.943 \\
\hline 17 & 46.67 & 58 & 48 & 50.89 \\
\hline 18 & 45.33 & 56 & 45 & 48.777 \\
\hline 19 & 45.33 & 54 & 43.5 & 47.61 \\
\hline 20 & 42.67 & 50 & 42 & 44.89 \\
\hline 21 & 40 & 46 & 40.5 & 42.167 \\
\hline Rata-rata & 55.114 & 64.305 & 59.367 & 59.605 \\
\hline
\end{tabular}

Berdasarkan tabel diatas diketahui bahwa laju (resapan) infiltrasi terbesar diperoleh pada lubang resapan kontrol sebesar $85 \mathrm{~cm} / \mathrm{jam}$ pada hari ke 7, dan nilai terendah sebesar $42.267 \mathrm{~cm} / \mathrm{jam}$ pada hari ke-21. Besarnya nilai rata-rata laju resapan yang diperoleh $59.605 \mathrm{~cm} / \mathrm{jam}$, berdasarkan (Sukaresmi,2011) laju infiltrasi yang diperoleh termasuk sedang. 


\section{Laju Resapan Lubang Biopori dengan Sampah Rumah Tangga (LRB1)}

Berdasarkan hasil analisis data uji untuk semua nilai laju resapan (infiltrasi) pada dengan bahan pengisi sampah rumah tangga, besarnya nilai laju infiltrasi rata-rata dari ketiga pipa uji ditunjukka pada Tabel 4.

Tabel 4 Nilai laju infiltrasi lubang resapan biopori LRB1

\begin{tabular}{|l|l|l|l|l|}
\hline \multirow{2}{*}{$\begin{array}{r}\text { Umur hari } \\
\text { ke }\end{array}$} & \multicolumn{3}{|c}{$\begin{array}{c}\text { Nilai Laju Infiltrasi (cm/jam) } \\
\text { Lubang Resapan Biopori 2 }\end{array}$} & \multirow{2}{*}{$\begin{array}{c}\text { (F) rata-rata } \\
\text { (cm/jam) }\end{array}$} \\
\cline { 2 - 4 } & LRB 1A & LRB 1B & \multicolumn{1}{|c|}{ LRB 1C } & \\
\hline 7 & 93 & 126 & 81.333 & 100.111 \\
\hline 8 & 48 & 76.5 & 72 & 65.5 \\
\hline 9 & 39 & 79.5 & 80 & 66.167 \\
\hline 10 & 46.286 & 85.5 & 58.667 & 63.484 \\
\hline 11 & 40 & 72 & 52.8 & 54.933 \\
\hline 12 & 36 & 66 & 68.571 & 56.857 \\
\hline 13 & 26.4 & 58.909 & 70.286 & 51.865 \\
\hline 14 & 24 & 57.6 & 68.571 & 50.057 \\
\hline 15 & 19.2 & 55.636 & 43.636 & 39.491 \\
\hline 16 & 22.5 & 57.6 & 46.8 & 42.3 \\
\hline 17 & 22.8 & 61.2 & 48 & 44 \\
\hline 18 & 20.73 & 55.64 & 43.64 & 40.003 \\
\hline 19 & 16.8 & 58.8 & 50.67 & 42.090 \\
\hline 20 & 18.67 & 56.4 & 44.4 & 39.823 \\
\hline 21 & 15.6 & 55.2 & 43.2 & 38 \\
\hline Rata-rata & 32.599 & 68.166 & 58.172 & 52.979 \\
\hline
\end{tabular}

Dari tabel diatas, dapat dilihat bahwa laju infiltrasi terbesar pada lubang resapan biopori bahan pengsi sampah rumah tangga terjadi pada hari ke-7 sebesar $100.111 \mathrm{~cm} / \mathrm{jam}$, dan terendah pada hari ke-21 sebesar $38 \mathrm{~cm} / \mathrm{jam}$. Dengan rata-rata nilai laju infiltrasi sebesar $52.979 \mathrm{~cm} / \mathrm{jam}$, hasil ini lebih rendah dari laju resapan kontrol yaitu sebesar 59,605 dan hal tersebut terjadi diperkirakan disebabkan oleh karena pada lubang pori tanah terjadi penyumbatan oleh sampah yang telah terurai sehingga pergerakan air menjadi melambat.Berdasarkan (Sukaresmi,2011) laju infiltrasi yang diperoleh termasuk sedang.

Akan tetapi jika dibandingan dengan laju resapan yang diperoleh dari penelitian Widyastuti. dkk (2016) pada model penelitian yang sama akan tapi menggunakan sampah dari kantin dimana kemampuan resapan tanah normalnya yang kecil yaitu $2 \mathrm{~cm} / \mathrm{jam}$ menghasilkan laju resapan biopori yang rendah, dan jauh lebih rendah dari hasil uji menggunakan sampah rumah tangga ini.

\section{Laju Resapan Lubang Biopori dengan Sampah Dedaunan (LBR2)}

Analisis laju resapan pada LRB dengan sampah dedaunan ditunjukkan olehTabel 5.

Tabel 5 Nilai laju infiltrasi lubang resapan biopori LRB2

\begin{tabular}{|l|l|l|l|l|}
\hline \multirow{4}{*}{\begin{tabular}{c}
\multirow{2}{*}{$\begin{array}{c}\text { Hari umur } \\
\text { sampah ke- }\end{array}$} \\
\cline { 2 - 4 }
\end{tabular}} & \multicolumn{3}{|c|}{$\begin{array}{c}\text { Nilai Laju Infiltrasi (Cm/Jam) } \\
\text { Lubang Resapan Biopori 3 }\end{array}$} & \multirow{2}{*}{$\begin{array}{c}\text { (F) rata-rata } \\
\text { LAm/jam) }\end{array}$} \\
\hline 7 & 185.142 & LRB 2B & $\begin{array}{c}\text { LRB } \\
\mathbf{2 C}\end{array}$ & \\
\hline 8 & 86.67 & 161.142 & 136.5 & 160.928 \\
\hline 9 & 90 & 121.714 & 99 & 103.571 \\
\hline 10 & 78 & 104.4 & 93.333 & 91.911 \\
\hline 11 & 80.4 & 106.8 & 86.4 & 91.2 \\
\hline 12 & 76.8 & 82 & 84 & 80.933 \\
\hline 13 & 79.2 & 89 & 85.2 & 84.467 \\
\hline 14 & 78 & 80.31 & 84 & 80.77 \\
\hline 15 & 69.6 & 77 & 81.6 & 76.067 \\
\hline
\end{tabular}




\begin{tabular}{|l|l|l|l|l|} 
Lanjutan & 69.6 & 81 & 84 & 78.2 \\
\hline 16 & 69.6 & 77.54 & 56.4 & 67.847 \\
\hline 17 & 68.4 & 76.62 & 57.6 & 67.54 \\
\hline 18 & 74.67 & 73.85 & 62.67 & 70.397 \\
\hline 19 & 54.8 & 69.23 & 55.2 & 59.743 \\
\hline 20 & 63.6 & 67.38 & 54 & 61.66 \\
\hline Rata-rata & 81.63213 & 91.7324 & 80.70487 & 84.69 \\
\hline
\end{tabular}

Berdasarkan hasil pada tabel di atas dapat dilihat bahwa, laju infiltrasi terbesar pada lubang resapan biopori dengan bahan pengsi sampah rumah tangga terjadi pada hari ke-7 sebesar $160.928 \mathrm{~cm} / \mathrm{jam}$, dan terendah pada hari ke-20 sebesar $59.743 \mathrm{~cm} / \mathrm{jam}$. Dengan rata-rata nilai laju infiltrasi sebesar $84.69 \mathrm{~cm} / \mathrm{jam}$ dan nilai ini lebih besar dari laju resapan LRBk yang besarnya $59,605 \mathrm{~cm} / \mathrm{jam}$, dengan selisih laju resapan sebesar $8,409 \mathrm{~cm} / \mathrm{jam}$. Jadi dengan penggunaan sampah dedauan dalam uji ini dapat meningkatkan kemampuan resapan biopori. berdasarkan (Sukaresmi,2011) laju infiltrasi yang diperoleh termasuk sedang sampai cepat.

\section{Laju Resapan Biopori pada pengisian sampah Jerami (LBR3)}

Hasil analisis data uji resapan LRB3 dengan sampah jerami dapat dilihat pada Tabel 6

Tabel 6 Nilai laju (resapan) infiltrasi lubang resapan biopori LRB3

\begin{tabular}{|c|c|c|c|c|}
\hline \multirow{2}{*}{$\begin{array}{l}\text { Umur sampah } \\
\text { hari ke }\end{array}$} & \multicolumn{3}{|c|}{ Laju resapan (infiltrasi) (cm/jam) } & \multirow{2}{*}{$\begin{array}{l}(\mathrm{F}) \\
\text { rata-rata }(\mathrm{cm} / \mathbf{j a m})\end{array}$} \\
\hline & LRB 3A & LRB 3B & LRB 3C & \\
\hline 7 & 250.286 & 98.4 & 189.333 & 179.34 \\
\hline 8 & 182.4 & 98.67 & 122.67 & 134.58 \\
\hline 9 & 208.8 & 87.6 & 126.7 & 141.033 \\
\hline 10 & 188.727 & 85.2 & 130.5 & 134.809 \\
\hline 11 & 179 & 87.6 & 112.8 & 126.467 \\
\hline 12 & 140 & 81.818 & 103 & 108.273 \\
\hline 13 & 134.182 & 90.55 & 104.7 & 109.811 \\
\hline 14 & 127 & 85.09 & 102.5 & 104.863 \\
\hline 15 & 123 & 81 & 99 & 101 \\
\hline 16 & 136.4 & 83 & 99 & 106.133 \\
\hline 17 & 120 & 80 & 99 & 99.667 \\
\hline 18 & 110 & 73.85 & 94.15 & 92.667 \\
\hline 19 & 97.85 & 74.77 & 87.69 & 86.77 \\
\hline 20 & 116 & 72.92 & 87.69 & 92.203 \\
\hline 21 & 113 & 72 & 85.85 & 90.283 \\
\hline Rata-rata & 148.443 & 83.49787 & 109.6389 & 113.86 \\
\hline
\end{tabular}

Sumber: hasil analisis

Berdasarkan hasil analisis tabel di atas, diketahui bahwa laju (resapan) infiltrasi terbesar pada LRB3 yang terjadi pada hari ke-7 adalah $179.34 \mathrm{~cm} / \mathrm{jam}$ dan nilai terendah diperoleh pada hari ke-19 sebesar $113.86 \mathrm{~cm} / \mathrm{jam}$, dengan rata-rata sebesar $113.86 \mathrm{~cm} / \mathrm{jam}$. Jika dibandingkan dengan laju resapan tanah kontrol, maka nilai laju resapan dengan sampah jerami diperoleh nilainya yang paling tinggi. Selisih laju resapan LRB3 terhadap kemampuan laju resapan LRBk adalah sebesar 54,255 cm/jam. Berdasarkan (Sukaresmi,2011) laju infiltrasi yang diperoleh termasuk kategori cepat. Jadi dengan biopori , organisme tanah yang berperan mengurai sampah di lubang biopori mampu membuat sampah menjadi mineral-mineral yang kemudian dapat larut dalam air, sehingga air tanah menjadi berkualitas karena mengandung mineralmineral.(Karuniastuti,2014).

Ditinjau berdasarkan besarnya kemampuan resapannya maka resapan maksimum terjadi ketika sampah organik telah dipasang pada biopori selama umur 7 hari, sedangkan setelah umur sampah 7 hari laju resapan sudah mulai menurun dan hal ini ditunjukkan terjadi pada ke tiga jenis ampah yang diujikan. 


\section{Karakteristik laju Resapan Lubang Resapan Biopori}

Karaketristik laju resapan biopori ditinjau terhadap waktu awal dilakukan pengujian yaitu saat 7 hari pamasangan dan waktu akhir dimana sampah sudah perlu mulai diganti yang ditinjau terhadap kecenderungan hasil analisis yang diperoleh. Berdasarkan hal tersebut pada Tabel 7 dapat dilihat besarnya nilai laju resapan rata-rata(F), dimana pada kondisi biopori tanpa pengisi sampah (LRBk) diperoleh $\mathrm{F}$ sebesar $85 \mathrm{~cm} / \mathrm{jam}$, pada pengisian dengan sampah rumah tangga (LRB1) diperoleh $\mathrm{F}$ sebesar $100.111 \mathrm{~cm} / \mathrm{jam}$, pada pengisian sampah dedaunan (LRB2) diperoleh $\mathrm{F}$ sebesar $160.928 \mathrm{~cm} / \mathrm{jam}$ dan pada pengisian dengan sampah jelami (LRB3) diperoleh F sebesar $179.339 \mathrm{~cm} / \mathrm{jam}$

Tabel 7.Laju Resapan (Infiltrasi) Lubang Resapan Biopori Hari Ke-7

\begin{tabular}{|l|l|l|l|l|l|}
\hline \multirow{4}{*}{} & \multirow{2}{*}{ Nama } & \multicolumn{3}{|c|}{ Uji jenis LRB } & \multirow{2}{*}{$\begin{array}{l}\text { F } \\
\text { (cm/jam) }\end{array}$} \\
\cline { 2 - 6 } hari ke-7 & $\mathrm{A}$ & $\mathrm{B}$ & $\mathrm{C}$ & 85 \\
\cline { 2 - 6 } & LRBk & 75 & 80 & 100 & 85 \\
\cline { 2 - 6 } & LRB1 & 93 & 126 & 100.111 & 100.111 \\
\cline { 2 - 6 } & LRB2 & 185.142 & 161.142 & 136.5 & 160.928 \\
\cline { 2 - 6 } & LRB3 & 250.286 & 98.4 & 189.333 & 179.339 \\
\hline
\end{tabular}

Sumber: hasil analisis

Memperhatikan hasil analisis laju (resapan) infiltrasi rata-rata di atas, maka berdasarkan (Sukaresmi,2011) laju infiltrasi yang diperoleh untuk LRBk termasuk sedang sampai cepat, LRB1 termasuk sedang sampai cepat, LRB2 dan LRB3 termasuk cepat. Jadi berdasarkan hasil ini ada potensi penggunaan sampah dedaunan dan jerami sebagai pengisi biopori LRB.

Selain itu memang benar yang dikatakan Widyastusi,dkk (2016) dan Bambang,dkk (2019), bahwa setiap jenis sampah memiliki karakter resapan yang berbeda-beda, baik dari segi lamanya menjadi kompos maupun kemampuannya meresapkan air. Pada uji ini kadang-kadang pada rentang waktu 7 sampai 21 hari proses biologi dalam biopori sedang berlangsung, masih sangat berpengaruh pada kemampuan resapan LRB sehingga nilai peresapan tidak dapat menurun secara linier mengikuti penambahan umur sampahnya. Akan tetapi secara umum karena proses pembusukan sampah didalam biopori telah berakhir maka pada umur sampah tersebut sudah dapat dilakukan pengantian.

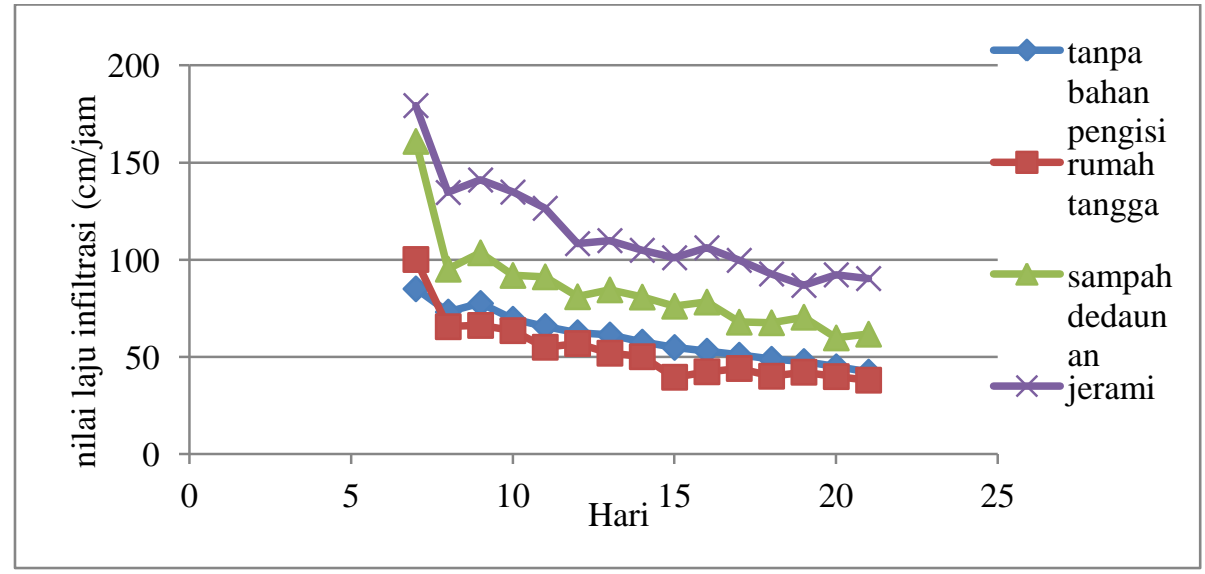

Gambar 7. Grafik hasil uji laju resapan biopori dari hari ke-7-21.

Berdasarkan hasil analisis data dan grafik di atas dapat dilihat bahwa laju resapan biopori dari sejak sampah berumur 7 hari, laju resapan yang terjadi semakin menurun dan rata-rata pada umur 21 hari sudah bisa diganti (kompus sudah dapat diambil) dengan jenis sampah yang baru. Laju resapan tertinggi diperoleh pada sampah jerami dan diikuti tertinggi ke dua sampah dedaunan dan yang ke tiga adalah sampah rumah tangga. Berdasarkan hasil ini maka pemakaian sampah dedaunan dan jerami lebih baik digunakan sebagai pengisi biopori dibandingkan dengan sampah rumah tangga. 


\section{SIMPULAN DAN SARAN}

\section{Simpulan}

1. Untuk lubang biopori tanpa bahan pengisi diperoleh nilai laju resapan tertinggi sebesar $85 \mathrm{~cm} / \mathrm{jam}$ dan terendah sebesar $42.167 \mathrm{~cm} / \mathrm{jam}$. Jenis sampah jerami diperoleh nilai laju resapan (infiltrasi) sebesar $179.34 \mathrm{~cm} / \mathrm{jam}$ dan nilai laju resapan terendah $86.770 \mathrm{~cm} / \mathrm{jam}$., dengan rata-rata $113.56 \mathrm{~cm} / \mathrm{jam}$. Pada pengisi dengan sampah dedaunan diperoleh laju resapan (infiltrasi) tertinggi sebesar $100.111 \mathrm{~cm} / \mathrm{jam}$ dan terendah $59.743 \mathrm{~cm} / \mathrm{jam}$, nilai rata-rata sebesar $84.69 \mathrm{~cm} / \mathrm{jam}$. Sedangkan pada jenis sampah rumah tangga diperoleh nilai laju resapan terendah sebesar $38 \mathrm{~cm} / \mathrm{jam}$ dan tertinggi sebesar $100.111 \mathrm{~cm} / \mathrm{jam}$, dan rata-rata $52.979 \mathrm{~cm} / \mathrm{jam}$.

2. Pada umur sampah 7 hari terjadi laju resapan tertinggi dari sampah uji, dan setelah sampah berumur 21 hari sudah seharusnya diganti dengan yang baru. Jenis sampah dedauan dan jerami sangat potensial digunakan sebagai pengisi LRB.

\section{Saran}

Uji dengan memperhitungkan jumlah lubang pori pipa perlu dilakukan kajian lebih lanjut untuk mengetahui efektivitas LRB

\section{DAFTAR PUSTAKA}

Asdak, C. (1995). Hidrologi dan Pengelolaan Daerah Aliran Sungai. Yogyakarta: Gadjah Mada University Press.

BR.Ginting, R. (2010). Laju Resapan Air Pada Berbagai Jenis Tanah Dan Berat Jerami Dengan Menerapkan Teknologi Biopori Di Kecamatan Medan Amplas. Universitas Sumatera Utara.

Brata, Kamir R. (2008). Lubang Resapan Biopori. Jurusan tanah Fakultas Pertanian IPB. Bogor.

Clothier, B. (2001). Infiltration. p. 237-277. In Soil and Environmental Analyses: Physical methods. In Smith et al. (Eds.). Marcel Dekker, Inc. United States of America.

Das, Braja M. (1995). Mekanika Tanah 1. Erlangga. Jakarta.

Habibiyah, A. W., \& Widyastuti, S. (2016). Pengaruh Jenis Sampah, Variasi Umur Sampah Terhadap Laju Infiltrasi Lubang Resapan Biopori (LRB). Wahana, 66(1), 33-39. https://doi.org/10.36456/wahana.v66i1.480

Hilwatullisan. (2011). Lubang Resapan Biopori (Lrb) Pengertian Dan Cara Membuatnya Di Lingkungan Kita. Media Teknik, Vol. 8(No. 2), Hal. 1-11.

Juliandari, M. (2013). Efektivitas Lubang Resapan Biopori Terhadap Laju Resapan (Infiltrasi). Jurnal Teknologi Lingkungan Lahan Basah, 1(1), 1-10. https://doi.org/10.26418/jtllb.v1i1.3441

Karuniastuti, N. (2014). Teknologi Biopori untuk Mengurangi Banjir dan Tumpukan Sampah Organik. Jurnal Forum Teknologi, 04(2), 64.

Martha, L. (2018). Studi Resapan Air Hujan Melalui Lubang Resapan Biopori (LRB) Sebagai Upaya Mereduksi Beban Drainase Di Universitas Islam Negri Sunan Ampel Surabaya (Issue 2) [UNIVERSITAS ISLAM NEGERI SUNAN AMPEL SURABAYA]. https://doi.org/10.1051/matecconf/201712107005

Menteri Negara Lingkungan Hidup No. 12 . (2009). Peraturan Menteri Negara Lingkungan Hidup Nomor 06 Tahun 2009 tentang Laboratorium Lingkungan. KementrianLingkungan,53.https://doi.org/10.1017/CBO9781107415324.004

Murbandono, H.S.L. (1999). Membuat Kompos. Penebar Swadaya. Jakarta.

Sibarani, R. T., \& Bambang, D. (2012). Penelitian Biopori Untuk Menentukan Laju Resap Air Berdasarkan Variasi Umur Dan Jenis Sampah Research Of Biopores To Determine The Rate Of Water Absorption Based On Variation In Age And Types Of Solid Waste Jurusan Teknik Lingkungan FTSP-ITS Surabaya Pend. Jurusan Teknik Lingkungan. FTSP. ITS-Surabaya, 1-14.

Sukaresmi, D. I. D., Megamendung, K., \& Bogor, K. (2011). Pada Penggunaan Lahan Pertanian Dan Pemukiman Mawar Kusumawardani Program Studi Manajemen Sumberdaya Lahan.

Sutanto. (2005). Permeabilitas Tanah (pp. 10-50).

Wikipedia. (2019). Infiltrasi (Hidrologi). https://translate.google.com/translate?u=https://en.wikipedia.org/wiki/Infiltration_(hydrology)\&hl=id $\& s l=e n \& t l=i d \&$ client $=$ srp \& prev=search. 